\title{
ANALISIS PENGARUH GEOMETRI PELEDAKAN TERHADAP FLY ROCK HASIL PELEDAKAN DI PT.BINTANG SUMATRA PACIFIC KEC. PANGKALAN KAB. LIMA PULUH KOTA PROVINSI SUMATERA BARAT
}

\author{
Riam Marlina $\mathbf{A}^{1)}$, Rizto Salia Zakri ${ }^{2)}$, Novrianto ${ }^{3)}$ \\ ${ }^{13)}$ Teknik Pertambangan, Sekolah Tinggi Teknologi Industri Padang \\ ${ }^{2)}$ Teknik Pertambangan, Universitas Negeri Padang \\ email: riztoszakri@gmail.com
}

\begin{abstract}
Abstrak
Abstrak: Kegiatan peledakan merupakan salah satu metode yang saat ini sering digunakan dalam kegiatan penambangan batubara maupun dalam proses pembongkaran batuan induk dalam penambangan batuan andesit. Selain menguntungkan kegiatan peledakan juga memiliki efek yang bisa berdampak negatif dan beresiko dapat merugikan kegiatan penambangan, salah satunya adalah Fly Rock. Fly Rock adalah fragmentasi batuan yang terlempar akibat hasil ledakan. Fragmentasi batuan yang terlempar melebihi radius aman dapat mengakibatkan kerusakan terhadap alat mekanis, cidera, bahkan kematian untuk manusia. Hal ini lah yang menyebabkan efek dari Fly Rock menjadi salah satu perhatian utama pada setiap kegiatan peledakan. Maka dari itu perlu mengetahui radius aman untuk alat dan manusia menurut rhicard and moore, geometri ideal untuk mendapatkan Fly Rock dalam radius aman dan mengetahui radius aman Fly Rock berdasarkan geometri usulan. Oleh karena itu Fly Rock akibat peledakan harus sesuai dengan keputusan menteri ESDM nomor 1287 K/30/MEM/ 2018 tentang pedoman pelaksanaan kaidah teknik pertambangan yang baik. Penelitian ini menggunakan metode penelitian terapan dengan persamaan empiris untuk mensimulasikan hasil perhitungan. Berdasarkan KEPMEN 1287K/30/MEM/ 2018 dari hasil pengukuran Fly Rock yang di lapangan maka didapatkan nilai lempar menurut rhicard and moore sebesar $204 \mathrm{~m}$ untuk peledakan pertama, $194 \mathrm{~m}$ untuk peledakan ke dua, dan $107 \mathrm{~m}$ untuk peledakan ke tiga. Geometri ideal untuk mendapatkan Fly Rock dalam radius aman yaitu berdasarkan C.J Konya diperoleh nilai Burden: $2 \mathrm{~m}$, spasi: $2,28 \mathrm{~m}$, stemming: $1,5 \mathrm{~m}$, kedalaman lubang: $6 \mathrm{~m}$, isian: 4,4 m, dan diameter lubang ledak: 3 inch, diperoleh nilai radius aman sebesar 195,72 m.
\end{abstract}

Kata kunci: Fly Rock, Geometri peledakan, Andesit, Peledakan

Abstract: Blasting activities are one of the methods currently used in coal mining activities and in the process of dismantling the source rock in andesite mining. Apart from being beneficial for blasting activities, it also has effects that can have a negative and risky impact on mining activities, one of which is Fly Rock. Fly Rock is rock fragmentation that is thrown off as a result of an explosion. Rock fragmentation that is thrown beyond the safe radius can result in damage to mechanical devices, injury, and even death to humans. This is what causes the effect of Fly Rock to become one of the main concerns of any blasting activity. Therefore, it is necessary to know the safe radius for tools and humans according to rhicard and moore, the ideal geometry to get Fly Rock in a safe radius and to know the safe radius of Fly Rock based on the proposed geometry. K / 30 / MEM / 2018 concerning guidelines for implementing good mining engineering principles. Based on KEPMEN 1287K / 30 / MEM / 2018 from the measurement results of Fly Rock in the field, the throw value according to rhicard and moore is $204 \mathrm{~m}$ for the first detonation, $194 \mathrm{~m}$ for the second detonation, and $107 \mathrm{~m}$ for the third detonation. The ideal geometry to get Fly Rock within a safe radius is based on CJ Konya, the value of Burden: $2 \mathrm{~m}$, space: $2.28 \mathrm{~m}$, stemming: $1.5 \mathrm{~m}$, hole depth: $6 \mathrm{~m}$, filling: $4.4 \mathrm{~m}$, and hole diameter explosion: 3 inch, the value of the safe radius is $195.72 \mathrm{~m}$.

Keywords: Fly Rock, Blasting Geometry, Andesite, Blasting 


\section{PENDAHULUAN}

PT Bintang Sumatra Pacific (PT BSP) adalah perusahaan yang bergerak dibidang industri pertambangan batu andesit dengan sistem tambang terbuka dan metode penambangan quary, proses pemberaian andesit menggunakan sistem peledakan. Tujuan peledakan umumnya adalah untuk memecahkan batuan.

Pekerjaan ini membutuhkan sejumlah energi yang cukup sehingga melebihi atau melampaui batas elastis batuan. Kegiatan peledakan dipilih dengan beberapa pertimbangan yakni lebih cepat dalam segi waktu pembongkaran dan lebih efisien dalam hal perawatan alat mekanis bila dibanding dengan menggunakan metode ripping-dozing.

Selain menguntungkan kegiatan peledakan juga memiliki efek yang bisa berdampak negatif, dan beresiko dapat merugikan kegiatan penambangan, salah satunya adalah Fly Rock. Fly Rock adalah fragmentasi batuan yang terlempar akibat hasil ledakan. Fragmentasi batuan yang terlempar melebihi radius aman dapat mengakibatkan kerusakan terhadap alat mekanis, cidera, bahkan kematian untuk manusia. Hal ini lah yang menyebabkan efek dari Fly Rock menjadi salah satu perhatian utama pada setiap kegiatan peledakan (Havis, dkk 2015).

Terjadinya Fly Rock yang berlebihan dari kegiatan peledakan dimana bisa karena kondisi kurangnya stemming dalam lubang ledak, perbandingan burden dengan diameter lubang terlalu kecil, atau adanya zona lemah dibagian freeface. Mekanisme terjadinya Fly Rock karena adanya rifling potensi lemparan lebih kearah atas, sementara pada fonomena face burst dan crater arah lemparan bisa terjadi pada sudut lebih rendah sehingga memungkinkan arah lemparan cukup jauh dan berdampak sangat berbahaya. (Suryadi,2018).

Lemparan batu yang jauh akibat mekanisme face burst perlu dikendalikan dengan proses mempersiapkan lokasi, proses desain pola pemboran dan pemasangan titik bor, proses pola ledak dan charging sheet, stemming.

Pengendalian agar tidak terjadinya rifling bisa dengan memastikan kolom stemming sesuai plan dengan menggunakan meteran, lakukan stemming dengan material yang khusus. Sedangkan untuk mengendalikan cratering kemiringan pemboran presisi tegak lurus dengan toleransi $3^{\circ}$, memastikan kolom jumlah isian dengan menggunakan meteran.

Jarak lemparan maksimum dari kegiatan peledakan tersebut berkisar antara 100 s.d. 500 meter, sementara jarak wilayah penambangan dengan jalan lintas hanya 500 meter, dengan kebun milik masyarakat 150-400 meter, dan fasilitas perusahaan seperti mes kantor berkisar 300-350 meter. Sehingga saat ini permasalahan Fly Rock menjadi perhatian khusus bagi perusahaan.

Berdasarkan laporan pengaduan di sekitar area penambangan terdapat tiga kali kejadian lemparan batuan yang mencapai lahan kebun milik masyarakat, timbangan dan jalan raya selama tiga bulan terakhir. Laporan menjelaskan bahwa lemparan batuan berada pada radius 100 hingga 500 meter dari sumber peledakan. Lemparan batuan tersebut menyebabkan kerusakan pada beberapa tanaman dan fasilitas perusahaan seperti timbangan dan kantor yang berada di sekitar perusahaan dan kebun milik masyarakat yang tidak bersedia lahannya dibebaskan oleh pihak perusahaan, sehingga muncul lah beberapa pengaduan.

Kejadian ini tentunya menyebabkan beberapa kerugian baik dari segi waktu maupun biaya perbaikan. Kondisi tersebut menjadi perhatian khusus yang perlu penyelesaian sesegera mungkin untuk meminimalisir kerugian yang akan terjadi di masa mendatang. 


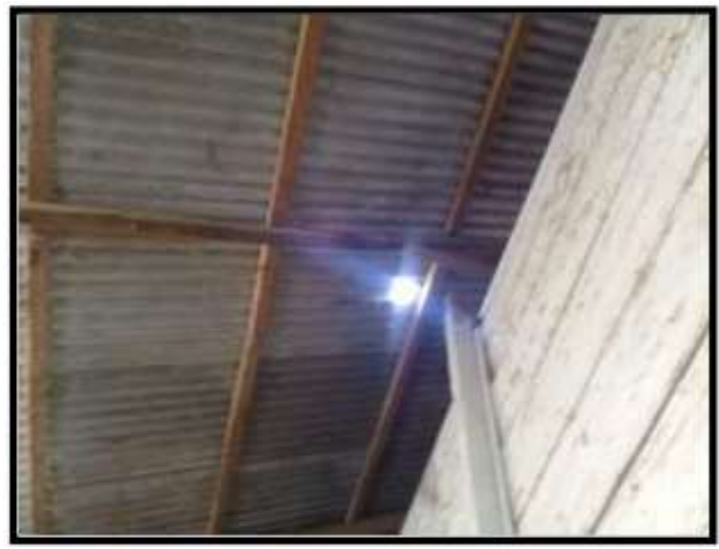

Gambar 1. Kerusakan Akibat Fly Rock

Sesuai penerapan yang dilakukan Adrian J. Moore dan Alan B. Richard (2005), radius aman alat ditentukan dari 2x lemparan terjauh aktual untuk mencegah terhadap hal-hal yang tidak terduga. Sedangkan menurut semua praktisi peledakan menetapkan radius aman unit adalah $300 \mathrm{~m}$ dan manusia $500 \mathrm{~m}$ dari lokasi peledakan.

Ketika pada kondisi semua unit dan manusia bisa di evakuasi, jika adanya Fly Rock tidak menjadi kekhawatiran yang serius (Arief Usman, dkk 2015).

\section{METODE PENELITIAN}

Penelitian ini dilaksanakan di zona 1 PT. Bintang Sumatra Pacific Nagari Manggilang Kabupaten Lima Puluh Kota.

Tahapan penelitian dijelaskan pada grafik di bawah ini :

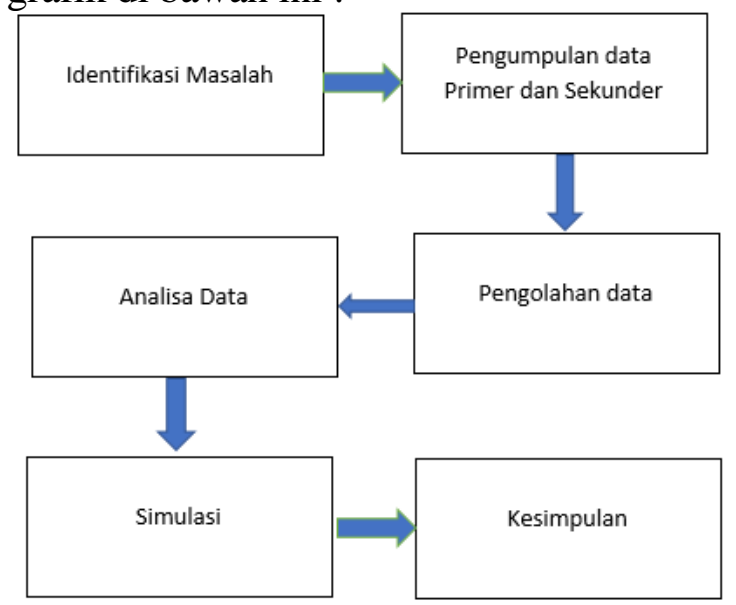

Gambar 2. Diagram Alir Penelitian

\section{Data dan Sumber Data}

Secara umum penelitian ini menggunakan pendekatan menggunakan data primer dan data sekunder, data primer terdiri atas :
a. Kedalaman stemming
b. Jarak burden awal dari freeface
c. Jarak lemparan fly rock terjauh dari lokasi peledakan

d. Ukuran Fly Rock yang terlempat jauh Sebagai penunjang penelitian digunakan beberapa data sekunder, diantaranya :
a. Sejarah dan profil perusahaan
b. Peta lokasi penambangan
c. Peta topografi
d. Peta kesampaian daerah
e. Spesifikasi bahan peledak
f. Jenis bahan peledak yang digunakan
g. Geometri rancangan
h. Data jarak lokasi peledakan dengan bangunan
i. Data jarak lokasi peledakan dengan jarak evakuasi alat.
j. Data jarak lokasi peledakan dengan jarak manusia.
k. Dan data pendukung lainnya.
Pengambilan data primer langsung dilakukan di lapangan selama kegiatan peledakan berlangsung, data ini selanjutnya dikompilasi dengan data sekunder untuk mendapatkan hasil.

\section{Teknik Pengumpulan Data}

1. Geometri Peledakan

Pengukuran geometri peledakan dilakukan sebelum proses peledakan dilakukan, yaitu setelah selesai pengeboran untuk mengetahu burden dan spasi peledakan

2. Hasil Fly Rock

Untuk pengumpulan data Fly Rock dilakukan dua tahapan, tahapan pertama adalah pengukuran jarak lemparan dengan menggunakan GPS, selanjutya koordinat lemparan terjauh diukur terhadap titik ledakan, sehingga didapatkan jarak leparan terjauh. Tahapan kedua adalah 
mengukur diameter batuan terbang yang terlempar paling jauh.

\section{Pengolahan Data}

Selanjtunya data yang diperoleh dilakukan perhitungan dengan beberapa metode. Untuk mengetahui geometri ideal menggunakan 2 persamaan RL. Ash dan CJ. Konya.

\section{Analisis Data}

Pada penelitian ini dilakukan analisis terhadap geometri aktual yang digunakan saat ini, yang menghasilkan fly rock. Berdasarkan hasil evaluasi geometri ini selanjutnya dilakukan perhitungan ulang geometri rencana dengan menggunakan beberapa metoda.

Selanjutnya berdasarkan hasil perhitungan dengan metode yang digunakan dipilih rekomendasi usulan yang paling baik.

\section{HASIL DAN PEMBAHASAN}

Berdasarkan hasil pengumpulan dan pengolahan data didapatkan hasil sebagai berikut :

1. Geometri aktual dan radius Fly Rock Data rekapitulasi hasil pengamatan pada zona 1 dapat dilihat pada Tabel 1, terlihat bahwa secara rata rata geometri peledakan di lapangan memiliki perbedaan yang tidak terlalu signifikan dari rencana yang telah ditetapkan. Geometri rencana didapatkan dari data sekunder perusahaan. Untuk perbedaan terbesar terlihat pada parameter stemming. Secara grafis perbedaan antara geometri aktual terhadap plan dapat dilihat pada tabel 1 .

Tabel 1 Data Geometri Peledakan Aktual

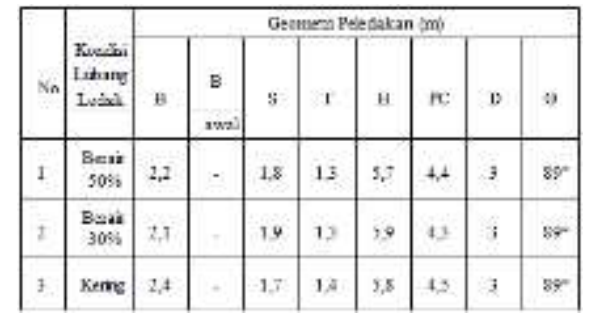

Tabel 2 merupakan tabel data dari Fly Rock dimana nantinya titik koordinat lokasi peledakan dan lemparan Fly Rock yang terjauh akan dimasukan ke software map source untuk mendapatkan berapa meter jarak dari lemparan Fly Rock itu dari lokasi peledakan.

Tabel 2 Pengumpulan Data Fly Rock

\begin{tabular}{|c|c|c|c|c|}
\hline \multirow{2}{*}{ No } & \multicolumn{2}{|c|}{ Titik Koordinat } & \multirow{2}{*}{$\begin{array}{c}\text { Jarak } \\
\text { Lemparan } \\
\text { (m) }\end{array}$} & \multirow{2}{*}{$\begin{array}{c}\text { Dimensi } \\
\text { Batuan } \\
(\mathrm{cm} \mathrm{x} \mathrm{cm})\end{array}$} \\
\hline & L.Peledakan & Fly Rock & & \\
\hline \multirow[b]{2}{*}{1} & $47 \mathrm{~N} 0694611$ & $47 \mathrm{~N} 0694430$ & & \multirow[b]{2}{*}{$12 \times 20$} \\
\hline & UTM 0001988 & UTM 0002082 & 204 & \\
\hline \multirow{2}{*}{2} & $47 \mathrm{~N} 0694611$ & $47 \mathrm{~N} 0694465$ & & \multirow{2}{*}{$9 \times 18$} \\
\hline & UTM 0001988 & UTM 0002119 & 194 & \\
\hline \multirow[b]{2}{*}{3} & $47 \mathrm{~N} 0694611$ & $47 \mathrm{~N} 0694594$ & & \multirow{2}{*}{$27 \times 29$} \\
\hline & UTM 0001988 & UTM 0002093 & 107 & \\
\hline
\end{tabular}

Radius Aman Radius aman didapatkan menggunakan data fly rock terjauh dari data peledakan di perusahaan, menurut richard and moore (2005) jarak aman merupakan 2x jarak Fly Rock terjauh dari suatu peledakan.

Tabel 3 Perbandingan Lemparan Fly Rock Aktual Dengan Teoritis

\begin{tabular}{|c|c|c|c|}
\hline Fly Rock & \multicolumn{3}{|c|}{ Teoritis } \\
\cline { 2 - 4 } Aktual & Face Burst $(\mathrm{m})$ & $\begin{array}{c}\text { Cratering } \\
(\mathrm{m})\end{array}$ & $\begin{array}{c}\text { Rifling } \\
(\mathrm{m})\end{array}$ \\
\hline$(\mathrm{m})$ & - & 169,29 & 5,75 \\
\hline 2 & - & 164,40 & 5,58 \\
\hline 1 & - & 143 & 4,89 \\
\hline 1 & \multicolumn{3}{|c|}{}
\end{tabular}

Dari tabel diatas maka bisa disimpulkan bahwa semakin dangkal kolom stemming, maka potensi lemparan Fly Rock akan semakin besar. Hal ini dipengaruhi oleh adanya kelebihan pengisian bahan peledak sehingga kolom stemming menjadi lebih dangkal. Selain itu, penurunan ketinggian stemming pada kondisi lubang ledak basah dikarenakan material stemming sebagian yang digunakan adalah cutting pengeboran. Dengan kondisi tersebut, maka derajat pengungkungan (degree of confinent) 
akan menurun sehingga berpotensi terjadinya Fly Rock.

Persiapan lokasi peledakan yang kurang baik dapat menyebabkan potensi bahaya Fly Rock. Hal ini disebabkan spoil hasil sisa peledakan pada saat persiapan tidak dibersihkan atau disingkirkan sehingga dapat terlempar ketika peledakan dilakukan dan berpotensi menjadi Fly Rock.

Disamping itu, kurang baiknya penanganan lubang ledak seperti tidak adanya identitas kedalaman lubang serta kondisi lubang mengakibatkan pengisian bahan peledak hanya dilakukan berdasarkan perkiraan. Sedangkan pada kondisi lubang ledak basah, penggunaan liner sering mengakibatkan kelebihan pengisian bahan peledak sehingga kolom stemming menjadi lebih dangkal. Selain itu, pada kondisi lubang basah sering dibiarkan dalam keadaan stemming kurang padat sehingga pengungkungan menjadi tidak sempurna dan berpotensi Fly Rock.

Dari semua peledakan didapatkan Fly Rock terjauh sebesar 204 meter, maka dari jarak tersebut didapatkan jarak radius aman sebesar dua kali 204 meter yaitu sebesar $408 \mathrm{~m}$.

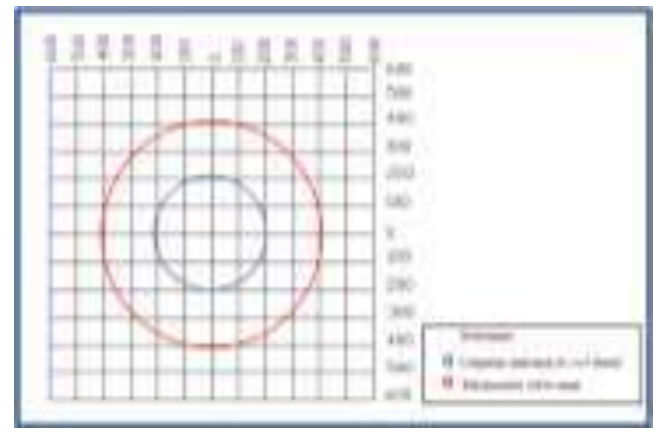

Gambar 3 Radius Aman Peledakan Aktual

2. Geometri Teoritis dan Radius Lempar Fly Rock

Untuk perhitungan geometri teoritis digunakan dua persamaan yaitu : a. R.L. Ash

Dari pengolahan menggunakan persamaan metode R.L.Ash maka didapatkan geometri peledakan dengan nilai burden $2 \mathrm{~m}$, spasi $3 \mathrm{~m}$, stemming $1 \mathrm{~m}$, kedakaman lubang $6 \mathrm{~m}$, kolom isian $5 \mathrm{~m}$, dan diameter lubang ledak 3 inch.

b. C.J. Konya

Dari pengolahan menggunakan persaman metode C.j Konya maka didapatkan geometri peledakan dengan nilai burden 2 $\mathrm{m}$, spasi $2,28 \mathrm{~m}$, stemming $2 \mathrm{~m}$, kedakaman lubang $6 \mathrm{~m}$, kolom isian $4 \mathrm{~m}$, dan diameter lubang ledak 3 inch.

Rekapitulasi geometri teoritis dapat dilihat pada tabel 5, berikut :

Tabel 5 Geometri Teoritis dan Radius Rempar Fly Rock

\begin{tabular}{|c|c|c|c|c|c|c|c|c|c|}
\hline \multirow{2}{*}{ No } & \multicolumn{7}{|c|}{ Geometr Peledakan } & \multicolumn{2}{|c|}{ Fly Rock (m) } \\
\cline { 2 - 9 } & & B & S & T & H & PC & D & $\begin{array}{c}\text { Face } \\
\text { Burst }\end{array}$ & Cratering \\
\hline 1 & R.L.A & 2 & 3 & 1 & 6 & 5 & 3 & 65.07 & 393 \\
\hline 2 & C.J & 2 & 2.28 & 2 & 6 & 4 & 3 & 55.29 & 97.86 \\
\hline
\end{tabular}

Dari tabel di atas maka dapat diprediksi Fly Rock yang memiliki jarak yang paling pendek dan baik adalah menggunakan teori C.j Konya yaitu dengan nilai stemming 2 meter dengan Fly Rock prediksi 97,86 m untuk cratering dan 55,29 m untuk face burst. Sehingga jarak radius aman di perusahaan PT. Bintang Sumatra Pacific dapat dikurangi dari 408 m menjadi dua kali 97,86 m yaitu sebesar $195,75 \mathrm{~m}$.

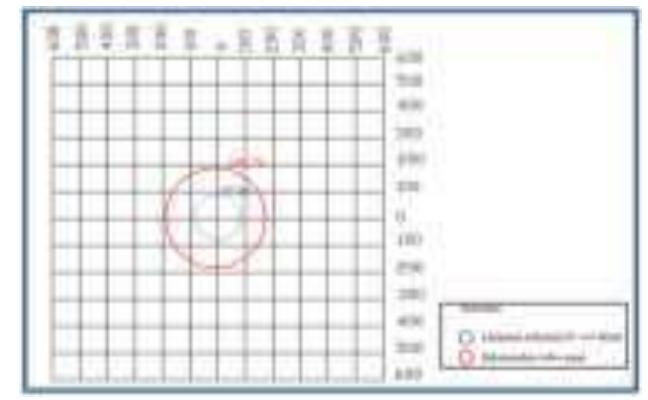

Gambar 4 Radius Aman Geometri Usulan 
3. Geometri Usulan dengan Geometri Aktual

a. Geometri peledakan pertama

Dari hasil penelitian penulis mendapatkan geometri peledakan dimana nilai burden 2,2 m, spasi $1,8 \mathrm{~m}$, stemming $1,3 \mathrm{~m}$, kedalaman lubang tembak $5,7 \mathrm{~m}$, kolam isian 4,4 $\mathrm{m}$ dan diameter 3 inch

b. Geometri Peledakan kedua

Dari hasil penelitian penulis mendapatkan geometri peledakan dimana nilai burden $2,1 \mathrm{~m}$, spasi $1,9 \mathrm{~m}$, stemming $1,3 \mathrm{~m}$, kedalaman lubang tembak 5,9 $\mathrm{m}$, kolam isian $4,3 \mathrm{~m}$ dan diameter 3 inch

c. Geometri Peledakan ketiga

Dari hasil penelitian penulis mendapatkan geometri peledakan dimana nilai burden $2,4 \mathrm{~m}$, spasi $1,7 \mathrm{~m}$, stemming $1,4 \mathrm{~m}$, kedalaman lubang tembak $5,8 \mathrm{~m}$, kolam isian 4,5 $\mathrm{m}$ dan diameter 3 inch

d. Geometri Usulan

Dari hasil perhitungan yang penulis lakukan maka penulis mengusulkan geometri peledakan menurut metode C.j Knya dimana nilai burden $2 \mathrm{~m}$, spasi $2,28 \mathrm{~m}$, stemming $2 \mathrm{~m}$, kedalaman lubang tembak $6 \mathrm{~m}$, kolam isian $4 \mathrm{~m}$ dan diameter 3 inch.

Berdasarkan dari geometri aktual dan geometri usulan, selanjutnya dapat dihitung potensi terjadinya Fly Rock secara teoritis sesuai dengan tabel 6 berikut :

Tabel 6 Geometri Usulan dan Geometri Aktual

\begin{tabular}{|c|c|c|c|c|c|c|c|c|c|c|}
\hline \multirow{3}{*}{ No } & \multicolumn{7}{|c|}{ Ovometn Redata } & \multicolumn{3}{|c|}{ Aly Anct (ar) } \\
\hline & & \multirow[b]{2}{*}{ B } & \multirow[b]{2}{*}{8} & \multirow[b]{2}{*}{$\mathrm{t}$} & \multirow[b]{2}{*}{ H } & \multirow[b]{2}{*}{$\mathrm{ec}$} & \multirow[b]{2}{*}{ b } & End & \multicolumn{2}{|c|}{ toent } \\
\hline & & & & & & & & Pengliunn & Agower & Coveringt \\
\hline 1 & \multirow{3}{*}{ Nesual } & 2,2 & 13 & $1, x$ & 3,2 & $a$ & 1 & 234 & 2,74 & 100.20 \\
\hline 2 & & 2.1 & 13 & 13 & 33 & 43 & 3 & 194 & 2,53 & 1046 \\
\hline 3 & & $2 \lambda$ & 13 & 34 & 9.8 & 49 & 3 & 107. & 4.90 & 36 \\
\hline & & & & & & & & Face burst & & $\operatorname{ming}$ \\
\hline 4 & Henan & 2 & 2.2 & 19 & 4. & $4 \pi$ & 1 & 25,20 & & \\
\hline
\end{tabular}

Dari tabel di atas ada beberapa rencana untuk meminimalisir jarak lemparan batuan di lapangan, yaitu menutup lubang ledak (stemming) dengan sepadat mungkin dan memilih ukuran material stemming dengan pas atau tidak terlalu besar, setelah dilakukannya penutupan stemming dengan padat, kemudian perubahan geometri peledakan.

Perubahan geometri peledakan perlu dilakukan uji coba untuk menghasilkan jarak lemparan batuan yang lebih kecil. Parameter geometri peledakan yang diubah adalah stemming.

Hal ini dilakukan karena secara statistik stemming memiliki hubungan yang sangat kuat terhadap jarak lemparan batuan. Selain itu secara teoritis stemming juga memegang peranan penting untuk mengunci energi di dalam lubang ledak agar optimal dalam memberai material ke arah samping dan memperkecil potensi energi keluar dari lubang ledak yang dapat menimbulkan Fly Rock.

4. Pengaruh Geometri Peledakan terhadap Fly Rock

Adapun pengaruh yang di hasilkan dari beberapa kali pengambilan data peledakan dan Fly Rock di lapangan yaitu : pertama face burst, face burst terjadi saat kondisi area peledakan memiliki jenjang yang mana jarak burden pada baris depan peledakan terlalu dekat dengan free face.

Kedua itu cratering, cratering terjadi saat tinggi stemming yang terlalu pendek serta terdapatnya bidang lemah pada lubang ledak.

Bidang lemah tersebut biasanya merupakan material broken dari hasil peledakan sebelumnya. Berdasarkan kondisi tersebut maka Fly Rock dapat terlempar ke segala arah dari lubang ledak yang di inisiasi. 
5. Fly Rock dan Lingkungan

Penelitian ini mengkaji tentang batu terbang (Fly Rock) yang dihasilkan dari peledakan tambang batu andesit. Hasil penelitian menunjukan jarak fly rock terjauh yang dihasilkan dari semua peledakan berjarak $204 \mathrm{~m}$, dengan radius aman $408 \mathrm{~m}$.

Jarak fasilitas perusahaan (kantor, gudang, mes dan lain-lain) dari area peledakan $\pm 400 \mathrm{~m}$ dan pemukiman yang paling dekat dengan perusahaan adalah Nagari Manggilang yang berjarak dari area peledakan $\pm 2 \mathrm{~km}$. Keputusan Menteri ESDM nomor 1287 K/30/MEM/ 2018 tentang pedoman pelaksanaan kaidah teknik pertambangan yang baik, disebutkan bahwa jarak aman peledakan bagi alat dan fasilitas pertambangan 300 (tiga ratus) meter serta bagi manusia 500 (lima ratus) meter.

Berdasarakan KEPMEN tersebut maka jarak fly rock yang dihasilkan dari kegiatan peledakan perusahaan melebihi ambang batas peraturan yang sudah ditetapkan dan sampai sampai ke fasilitas perusahaan.

\section{KESIMPULAN}

Dari penelitian yang telah dilakukan dapat disimpulkan sebagai berikut:

1. Radius lempar menurut Rhicard and moore diperoleh nilai radius lempar Fly Rock sebesar 204 m untuk peledakan pertama, $194 \mathrm{~m}$ untuk peledakan ke dua, dan $107 \mathrm{~m}$ untuk peledakn ke tiga. Sesuai dengan ketetapan mentri ESDM yaitu radius aman alat $300 \mathrm{~m}$ dan radius aman manusia $500 \mathrm{~m}$.

Maka radius aman yang ada pad kepmen tidak sesuai dengan panduan penentuan jarak aman sebesar 2x jarak lemparan terjauh pada PT. Bintang Sumatra Pacific.

2. Geometri ideal untuk mendapatkan Fly Rock dalam radius aman pada PT. Bintang Sumatra Pacific yaitu berdasarkan C.J Konya diperoleh nilai Burden: 2 m, spasi: 2,28 m, stemming: $2 \mathrm{~m}$, Kedalaman lubang: $6 \mathrm{~m}$, isian: 4,4 $\mathrm{m}$, dan diameter lubang ledak: 3 inch.

3. Radius aman Fly Rock berdasarkan geometri usulan yaitu stemming $2 \mathrm{~m}$, dan burden awal nya $2 \mathrm{~m}$ diperoleh nilai radius aman sebesar $195,72 \mathrm{~m}$.

\section{DAFTAR PUSTAKA}

Arief Usman, Sudarsono, Indah Setyawati.2015. Kajian Radius Aman Alat Gali Muat terhadap Flyrock Peledakan pada Pit 4500 Blok 12 PT Trubaindo Coal Mining Kutai Barat Kalimantan Barat. Jurnal Teknologi Pertambangan Volume 1 Nomor 1 Periode Maret - Agustus 2015

Arsandi Mukti. 2016. Mekanisme Pecahnya Batuan. https : // muktiar sandi. word press. com (diakses tanggal 25 juni 2020)

Aulia Himmatul Putri. Yuliadi. Marmer Dwihandoyo. 2017 Analisis Arah dan Jarak Lemparan Fly Rock Akibat Kegiatan Peledakan di PT Dahana Jobsite PT Adaro Indonesia, Kabupaten Tabalong, Provinsi Kalimantan Selatan. Program Studi Pertambangan, Fakultas Teknik, Universitas Islam Bandung

Havis Abdurrachman. 2015. Analisis Flyrock ntuk Mengurangi Radius Aman Alat pada Peledakan Overburden Penambangan Batubara. Proceeding Seminar Nasional Kebumian Ke-8 Academia Industry Linkage 15-16 Oktober 2015 Graha Sabha Pramana.

Hendra Romie. 2015. Pola Peledakan. https://www.slideshare.net/mobile (diakses tanggal 3 februari 2020) 
Kementrian ESDM 1827. 2018 Tentang pedoman Pelaksanaan Kaidah Teknik Pertambangan Yang Baik. Mentri Energi Dan Sumber Daya Minerel Rpublik Indonesia.

Konya, C.J. 1991. Rock Blasting and Overbreak Control; Precision Blasting Services. U.S. Department of Transportation Federal Highway Administration, Contract No. DTFH61-90R00058, (NTIS No. PB 97-186548)

Koesnaryo 1988. Bahan Peledak dan Metode Peledakan. Fakultas Tambang UPN "veteran" Yogyakarta.

Monjezi M. 2010 Prediction of flyrock and backbreak in open pit blasting operation: a neuro-genetic approach. Saudi Society for Geosciences

Nadhif Syeban. Marsudi. M. Khalid Syafrianto. 2019. Kajian Batu Terbang (Fly Rock) Untuk Mengurangai Radius Aman Pada Peledakan Penambangan Granodiorit Pt. Total Optima Prakarsa Peneriman Kecematan Sungai Pinyuh Kabupaten Mempawah Kalimantan Barat. Teknik Pertambangan Universitas Tanjungpura Pontianak

Richard, Alan B.,Adrian J.Moore. 2005. Golden Pike Cut Back Fly Rock Control and Calibration of a Predictive Model. Terrock Consulting Engneers, Australia.

Saptono Singgih, 2006. Teknik Peledakan. Jurusan Teknik Pertambangan, Fakultas Teknologi Mineral, UPN “ veteran” Yogyakarta

Suryadi. Kopa Raimon. 2019. Analisis Geometri Peledakan untuk Meminimalisir Jarak Lemparan Batuan (Flyrock) pada Peledakan Tambang Terbuka PT Ansar Terang Crushindo II
Pangkalan Sumatera Barat Dengan Visualisasi menggunakan Drone DJI Phantom 4. Jurusan Teknik Pertambangan FT Universitas Negeri Padang 